\title{
Dynamic-energetic balance of agricultural tractors: active systems for the measurement of the power requirements in static tests and under field conditions
}

\author{
Daniele Pochi, Roberto Fanigliulo, Mauro Pagano, Renato Grilli, Marco Fedrizzi, \\ Laura Fornaciari
}

Consiglio per la ricerca e la sperimentazione in agricoltura, CRA-ING, Unità di ricerca per
l'ingegneria agraria, Agricultural Engineering Research Unit, Monterotondo (Roma), Italy

\begin{abstract}
Modern tractors are characterized by the introduction of devices designed to increase the operative performances of the machines, such as systems for monitoring and controlling various functions (through a massive use of electronics and hydraulics), or deputed to improve the comfort of the driver (paying more attention to ergonomics, air-conditioning, noise and vibration). Such devices need energy to be operated, affecting the energetic balance of the tractor. In this context, the availability of suitable methodologies and instrumental systems could be useful to provide objective, accurate and reliable measurements of the performances of the tractors under different conditions, also considering the power requirements from ancillary services and/or simulating the coupling with operating machines. The tests on the performances of tractors are now made using different methods, including the trial codes issued by the OECD Codes. Beyond their undoubted validity, they fix standard test conditions that often do not adequately represent the operative reality, so that, much remains to investigate on the actual performances provided by the tractors. From this point of view and with reference to fixed point tests, a test bench was developed for the measurement of the power required by various devices, such as transmission and air conditioning. It was used in experimental tests on a tracked tractor and on a wheeled tractor, aimed at validating the test device, measuring the power absorp-
\end{abstract}

Correspondence: Daniele Pochi, Unità di ricerca per l'ingegneria agraria, Via della Pascolare, 16, 00015 Monterotondo (Rome), Italy.

Tel. +39.06.90675232 - Fax: +39.06.90625591.

E-mail: daniele.pochi@entecra.it

Key words: agricultural machines, transducers, data acquisition system, operative performance, tractor test bench.

Contributions: the authors contributed equally.

Conflict of interests: the authors declare no potential conflict of interests.

CC Copyright D. Pochi et al., 2013

Licensee PAGEPress, Italy

Journal of Agricultural Engineering 2013; XLIV(s2):e84

doi:10.4081/jae.2013.s2.e84

This article is distributed under the terms of the Creative Commons Attribution Noncommercial License (by-nc 3.0) which permits any noncommercial use, distribution, and reproduction in any medium, provided the original author(s) and source are credited. tion related to the rotational speed of the organs of propulsion and to the characteristics curves, in order to quantify the power drawn by the transmission and by the air conditioning and assess the residual power for other tractor functions. As to field conditions, a study is being conducted at CRA-ING, within the project PTO (Mi.P.A.A.F.), to develop a mobile test bench aimed at evaluating the power required by different operations, such as self displacement, traction, use of power take off, their combination. The system simulates such operations by applying to the tractor, by means of a system of sensors and actuators operated by feedback signals, work cycles combining force of traction, p.t.o. torque, hydraulic power, derived from data recorded during real field test with agricultural machines.

\section{Introduction}

Modern tractors are characterized by the introduction of devices designed to increase the operative performances of the machines, such as systems for monitoring and controlling various functions (through a massive use of electronics and hydraulics), or deputed to improve the comfort of the driver (paying more attention to ergonomics, air-conditioning, noise and vibration). Such devices need energy to be operated, affecting the energetic balance of the tractor (Pochi $e t$ al., 1996; Bodria et al., 2006; Al-Suhaibani et al., 2010).

In this context, the availability of suitable methodologies and instrumental systems could be useful to provide objective, accurate and reliable measurements of the performances of the tractors under different conditions, also considering the power requirements from ancillary services and/or simulating the coupling with operating machines (Casini Ropa, 1975; Gasparetto et al., 1985; Fanigliulo et al., 2004).

The tests on the performances of tractors are now made using different methods, including the trial codes issued by the OECD (2005). Beyond their undoubted validity, they fix standard test conditions that often do not adequately represent the operative reality, so that, much remains to investigate on the actual performances provided in field by tractors (Marsili and Servadio, 2001).

The main items for further studies are: at fixed point, the distribution of engine power to move the various internal components of the tractor (gearbox, transmission, air conditioning, hydraulic system, etc.); under actual field conditions, the work of hydraulic lift in terms of actual control of the mounted implement and the work for self-displacement on different surfaces.

This work is framed in the context of activities the goal of which is to establish a test protocol for measuring the dynamic and energetic balance of the tractor in real operating conditions, on completion and integration of the tests according the OECD standards and in support of ENAMA protocols for the tests of operating machines. 
In the first step it has been faced the aspect of the relief, in tests at a fixed point, of the power required for the operation of various organs of the tractor. To do this, a dynamometric brake, commonly used in power-take-off tractor tests, has been combined with a special device (which is presented below for a description) suitably designed for accurate measurements of the power required by different tractor services. The detailed information provided allows better evaluation of actual power requirements of the machines for primary and secondary soil tillage. Finally, the second part of the paper reports the results of tests aimed at measuring the power absorbed by the motion transmission systems from the flywheel to the organs of propulsion of two tractors and by the air conditioning system of a tractor.

Furthermore, the study of the performances of tractors under field conditions became the main subject of the research project "Methodologies and instrumentations for the measurement of the Performances of Tractors under Operative conditions - Integration of the tests indicated in the OECD Codes No. 2 and 5" (acronym: PTO Mi.P.A.A.F., DM 2148 - 20/03/2009). The projects aims at developing a mobile test bench that, coupled to the tractor, is capable to simulate the action of operating machines, both passive (pulled machines as ploughs) and driven by the tractor PTO.

The system is based on hydraulic actuators generating the desired load condition on the tractor (force of traction and/or torque at the PTO, hydraulic power) controlled by electronic elements. A feedback system allows the application of work cycles based on the combination of data recorded during the test of real operating machines. Basing on such an approach it should be possible to develop a test methodology based on standard simulated work cycles that allow to test tractors under real conditions (in field or road, in plain or in hilly surfaces etc) and to reliably compare their performances. The project is in progress and in the following a description of the equipment already made will be provided.

\section{Materials}

\section{Static tests}

\section{Equipment used for static test}

The bench for the testing of tractors, made at the headquarters of CRA-ING (Monterotondo, Italy), is arranged in two separate rooms: the actual test room and the cockpit.

Inside the test room, there is an electro-magnetic dynamometric brake for testing, at the PTO, of tractors with maximum power of $300 \mathrm{~kW}$.

Backward, the brake is connected by means of a driveshaft, to a three-phase asynchronous electric motor (Figure 1) with nominal power of $30 \mathrm{~kW}$ (at $1000 \mathrm{~min}^{-1}$ ), controlled by an inverter, which allows adjustment of frequency and voltage in order to control the speed and torque, both positive and negative (the torque is measured by a load cell specially installed to lock the stator of the electric motor).

A system of $8 \mathrm{~W}$ resistances (installed in series) has the function of dissipating as heat, the electric energy generated by the conversion of the kinetic energy of the rotor while it works in addition to the dynamometric brake. The electric motor was used in tests aimed to study of the absorption of power by the transmission and subsidiary systems.

On one side of the test bench, a box houses a weight fuel consumption measurer, suitably connected to the tractor feed (Figure 2). Changes in weight, referring to the time they have been detected, to measure the time consumption and therefore the introduction of fuel.

The cockpit houses the console for the control of the brake and the electric motor, and for monitoring test parameters and plant working parameters. All data (brake torque, torque electric motor and turns of both) are collected by a computer equipped with a PCI card for immediate processing.

\section{Tractors used in static tests}

The tests were conducted on a tractor with steel tracks (A) and on a wheeled tractor (B). Their main characteristics are summarized in Table 1.

\section{Test of tractors under operative conditions}

The realization of the mobile test bench mentioned in the point 2 is still in progress. It will be based on a vehicle (pulled by the tractor) modified according to Figure 3 that schematically shows the main interventions to be made on an old truck.

The test bench in his final version will be capable to apply to the tractors load conditions as force of traction, torque at the PTO and hydraulic power requests (and the combination of them), while travelling on any type of surface.

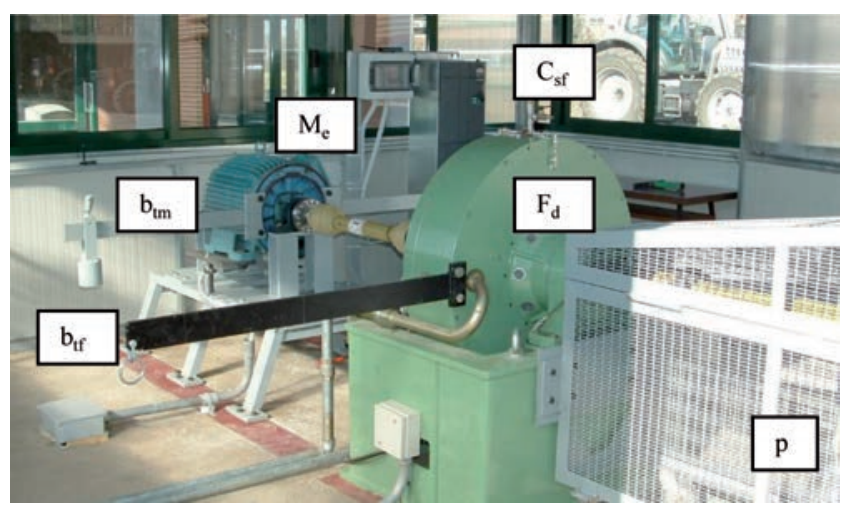

Figure 1. Test bench: $F_{d}$, dynamometric brake; $M_{e}$, three-phase electric motor connected to $F_{d}$ by means of a cardan joint; $C_{s}$; frequency static converter; $B_{t}$, steel bars used for calibrating the load cell of the dynamometric brake; $\boldsymbol{b}_{t m}$, steel bars used for calibrating the load cell of the electric motor; p, protection frame of the cardan joint between dynamometric brake and tractor power take off.

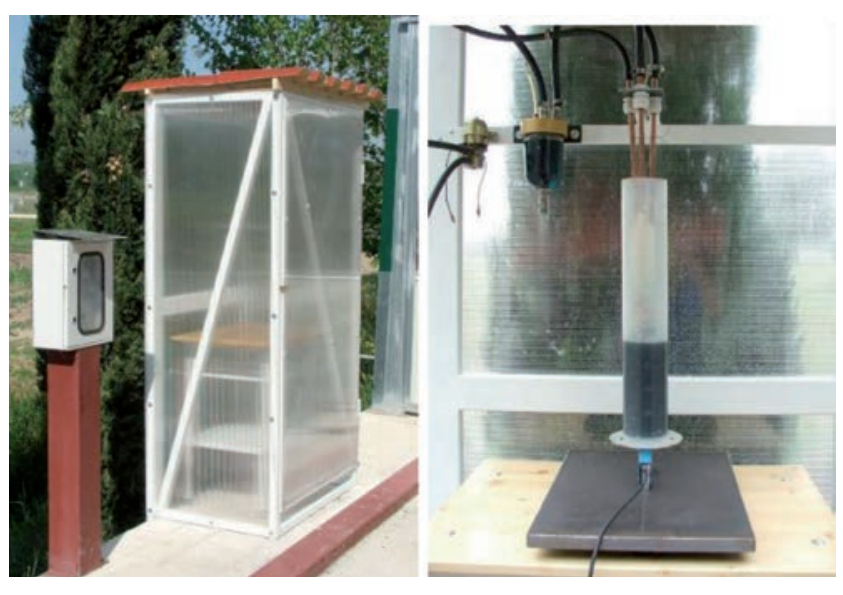

Figure 2. Left: box with the fuel consumption measurer. Right: weight fuel consumption measurer. 


\section{Methods}

\section{Static tests}

The tractors were positioned at the dynamometric brake with wheels/tracks lifted from the ground. The power take off was connected to the brake by means of a drive shaft, as second drive shaft linked the brake and the electric motor, as described above. Before the tests, the actual transmission ratios between engine drive shaft, PTO, final transmission and peripheral speed of tires and tracks were recorded on both tractors (Table 2).

The tests were divided into three phases: 1) determination of the characteristic curves, at the PTO, of each tractor according to the OECD standard (using only the dynamometric brake, with and without transmission and air conditioning system working). 2) relief of the power requirements by the connection of pre-selected transmission gear ratios, by means of the combined action of the electric motor and the Brake, starting from the maximum power characteristic curve. 3) determination of the power absorbed by the air conditioning in the cab of the tractor B, by means of both brake and electric motor, always starting from the curve of maximum power.

\section{Characteristic curves of the engines}

All the test providing the engine characteristic curves were per-

Table 1. Main characteristics of the tested tractors.

\begin{tabular}{|c|c|c|c|}
\hline & Main charactaistics & Tractor $A$ & Tractor B \\
\hline \multirow{4}{*}{ Engine } & Cylinders (a) / displacentent (cm') & $4 / 4000$ & $4 / 4000$ \\
\hline & Nonumal powa (kIV) / agine speed $\left(\min ^{-1}\right)$ & $75 / 2500$ & $84 / 2300$ \\
\hline & Max powror argine speed ( $\left.\min ^{-1}\right)$ & 2500 & 2300 \\
\hline & Maximum torque. $\mathrm{Nm}$ / agine speed ( $\min ^{-1}$ ) & $355 / 1400-1600$ & $395 / 1400 / 1600$ \\
\hline \multirow{9}{*}{ Tranzmission } & Gear bex & $\begin{array}{l}4 \text { syuchronized gears, } 2 \text { gear } \\
\text { ramess with speed redica }\end{array}$ & 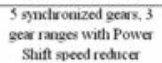 \\
\hline & Rapporti (in) & $16 \mathrm{FW}+16 \mathrm{Rev}$ & $20 \mathrm{AV}+20 \mathrm{Rev}$ \\
\hline & Reversing idler & necthanic. snnclironized & mectuanic. syuxhronized \\
\hline & Nonainal speed - minumum / $\operatorname{maximum}\left(m s^{-1}\right)$ & $0.17 / 3.05$ & $0.14 / 11.11$ \\
\hline & PTO clutch & unttiple discs in of bath & multiple disss in oil bxath \\
\hline & PTO speed gear adopted in the tots $\left(\mathrm{min}^{-1}\right)$ & $\begin{array}{l}750 \text { mini }^{-1} \text { (at noniunal } \\
\text { speed) }\end{array}$ & $\begin{array}{l}540 \text { Eco }\left(743 \mathrm{~min}^{-4} \text { at }\right. \\
\text { nouminal speed) }\end{array}$ \\
\hline & Max argine speed with PTO ansation (man ${ }^{-1}$ ) & 2980 & 2512 \\
\hline & Max cagine speed without PTO insation ( $\min ^{-4}$ ) & 2985 & 2518 \\
\hline & Transmision ratio azine drive staft PTO & 3.123 & 3093 \\
\hline
\end{tabular}

Table 2. Characteristics of the gear boxes of the two tractors with reference to the ratios adopted in the tests.

\begin{tabular}{|c|c|c|c|c|c|c|c|c|c|}
\hline \multicolumn{5}{|c|}{ Tractor $\mathrm{A}$} & \multicolumn{5}{|c|}{ Tractor B } \\
\hline reducer & $\begin{array}{l}\text { geas } \\
\text { range }\end{array}$ & gear & 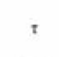 & $\begin{array}{l}v_{p}{ }^{*} \\
m z^{-4}\end{array}$ & gear range & gear & $\begin{array}{l}\text { Power- } \\
\text { Shift }\end{array}$ & $\tau$ & $\begin{array}{l}\mathrm{v}_{\mathrm{p}} \\
\mathrm{m} \mathrm{s}^{-4}\end{array}$ \\
\hline \multirow{8}{*}{$\begin{array}{l}\text { Low } \\
\text { gpeed } \\
\text { (R) }\end{array}$} & \multirow{4}{*}{ Tutle } & 1 & 183.53 & 0.45 & \multirow{6}{*}{$\begin{array}{l}\text { Low weed } \\
(R)\end{array}$} & \multirow{2}{*}{1} & snal & 36051 & 0.55 \\
\hline & & 2 & 164.31 & 0.51 & & & have & 30180 & 0.66 \\
\hline & & 3 & 127.15 & 0.66 & & \multirow{2}{*}{3} & mall & 24404 & 081 \\
\hline & & 4 & 9236 & 090 & & & have & 170.19 & 1.17 \\
\hline & \multirow{4}{*}{ Hare } & 1 & 177.47 & 0.47 & & \multirow{2}{*}{5} & nall & 129.09 & 154 \\
\hline & & 2 & 136.26 & 0.61 & & & hase & 8835 & 225 \\
\hline & & 3 & 106.60 & 0.78 & \multirow{6}{*}{$\begin{array}{l}\text { Medinus } \\
\text { speed (M) }\end{array}$} & \multirow{2}{*}{1} & mal & 203.67 & 0.98 \\
\hline & & 4 & 76.81 & 1.08 & & & lase & 140.86 & 1.41 \\
\hline \multirow{8}{*}{$\begin{array}{l}\text { Hilh } \\
\text { speed (V) }\end{array}$} & \multirow{4}{*}{ Turtle } & 1 & 71.4 & 1.17 & & \multirow{2}{*}{3} & smal & 144.16 & 1.74 \\
\hline & & 2 & 5486 & 152 & & & hase & 7851 & 253 \\
\hline & & 3 & 4240 & 196 & & \multirow{2}{*}{5} & snal & 3991 & 3.32 \\
\hline & & 4 & 31.01 & 2.69 & & & hase & 40.67 & 4.89 \\
\hline & \multirow{4}{*}{ Hase } & 1 & 59.35 & 1.40 & \multirow{5}{*}{$\begin{array}{l}\text { Helh speed } \\
\text { (V) }\end{array}$} & \multirow{2}{*}{1} & snal & 60.12 & 3.31 \\
\hline & & 2 & 4582 & 182 & & & lare & 47.12 & 422 \\
\hline & & 3 & 3535 & 236 & & \multirow{2}{*}{3} & snal & 39.03 & 5.09 \\
\hline & & 4 & 25.74 & 324 & & & hase & 26.44 & 7.51 \\
\hline & & & & & & 5 & snal & 1993 & 997 \\
\hline
\end{tabular}

* vp, peripheral velocity of wheels and steel tracks referred to the engine nominal speed of the two tested tractors. formed in accordance with the requirements of the OECD Code No. 2 for the tests at the PTO of tractors. The environmental parameters that can affect the results of the trials have been monitored, such as, for fuel consumption, the temperature of fuel, lubricating oil and air and the atmospheric pressure. This made it possible to standardize the data using correction functions officially recognized ${ }^{[1]}$, which take into account the above parameters.

\section{Power absorbed by the transmission}

\section{Characteristic curves with clutched gear}

Starting from the characteristic curves under conditions of maximum fuel delivery, the clutching of a specific gear box ratio determines a resistive torque that the engine must overcome to allow the rotation of transmission system and wheels or tracks. As a consequence, the power requirement increases depending on the rotational speed of wheels (or tracks) and a new balance working point will be reached on the engine speed-power diagram (and on engine speed-torque diagram as well). As previously mentioned, the tractors at the dynamometric brake were lifted from the ground in order to detect the characteristic curves of the motor without and with gear. Comparing them, the power absorbed by the transmission can be evaluated for each gearbox ratio, throughout the range of engine operation. This procedure was applied, on both tractors, for some gearbox ratios. The results were reported in diagrams.

Tests with the electric motor connected to the dynamometric brake

The coupling of the dynamometric brake with the electric motor allows rapid reproduction of single points of the characteristic curves corresponding to engine working conditions observed during field operations. For each point the system provides accurate measurement of the total power and of the power absorbed by the transmission. The test procedure is based on the following points:

1. adjustment, by means of the dynamometric brake, of engine speed, torque and power on values corresponding to desired operative conditions and acquisition of the data;

2. clutching of a gearbox ratio: this determines, on the engine speedtorque and speed-power diagrams, new points of equilibrium of the system, consisting on reduction of the speed and variation of torque and power measured by the data acquisition system connected to the brake;

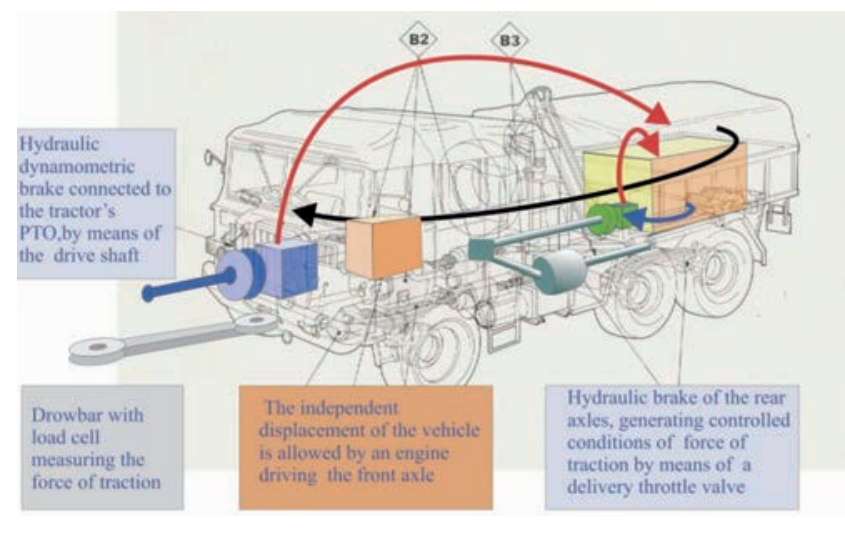

Figure 3. Vehicle to be modified in order to lodge equipments, instruments and control systems generating the simulate operative conditions derived from field tests with real operating machines. 
3. restoration of initial conditions of point 1 , by means of a positive torque provided by the electric motor, bringing the engine speed, torque and power to the initial values detected by acquisition system. The electric motor then provides a couple (measured by the load cell) and a power equal to that absorbed by the insertion of the specific gear box ratio;

4. disconnection of the gear-box and elimination of the positive torque of the electric motor, returning to the conditions set out in point 1 (without the help of the electric motor).

According to such a procedure, it is possible to move along the curve of power (it can be the curve of maximum power or can be obtained under condition of partial fuel introduction) and to observe further points of working in order to measure the power required by the insertion of different gear-box ratios and by auxiliary devices.

The power requirements by transmission were measured starting from the full admission curves of power of each tractor. After having identified a point of working near the maximum power, the power required at the insertion of different gear box rations were measured adopting the above described procedure.

\section{Tests of tractors under operative conditions}

The mobile test bench should allow to simulate the action of any operating machine coupled to the tractor. This is possible through adjustments and combination of the different types of solicitations applicable to the tractor during its travel. As to the origin of said solicitations, the workgroup involved in the project (CRA-ING - Agricultural Machinery Testing Center, certified by ACCREDIA as Lab. No. 1141 according the standard EN ISO/EC 17025:2005), during more than 15 years, has been making tests on agricultural equipments, recording field test data on force of traction, p.t.o. torque, velocity, slip and other significant parameters, especially with regard to soil tillage machines and sowing machines. Such data series can be indefinitely reproduced by the feedback control system of the mobile test bench. Combining the data series of different operations, for time intervals representative of their real execution in farm, will allow to "build" artificial work cycles, applicable to the tractor under test, in a pre-defined test track with different conditions of surface, slope. The work cycles will be representative of the typical use of the tractors during the year, and will be calibrated on the type of machines and on their dimensions and power class. Similar tractors will undergo the same work cycle. The method will provide information on the real performances of the tractors and reliable comparative data among machines of the same category.

\section{Results}

\section{Static tests}

The diagrams of Figure 4 show, for each tractor, a series of curves, obtained at the dynamometric brake, which describe the behaviour of torque and power provided by the engine and the fuel consumption under three conditions of working.

It can be noticed the almost perfect overlap of the curves of consumption, which indicates that in all the tests, the engine globally provided the same power. As to power and the torque, each of them presents three different curves monitored by the system and depending on the different conditions of working: the higher curve refers to the performances of the sole engine, as the other two are related to new points of balance determined by the insertion of two gearbox ratios (the lower refers to the ratio corresponding to higher speed) that made the wheels turn. Each curve describes the torque and the power still available (at the p.t.o.) and measured by means of the dynamometric brake, after the insertion of a gearbox ratio. When the engine works in given operating conditions (of power, torque and fuel consumption) the insertion of gearbox ratio represents an additional resistant load. As a conse-
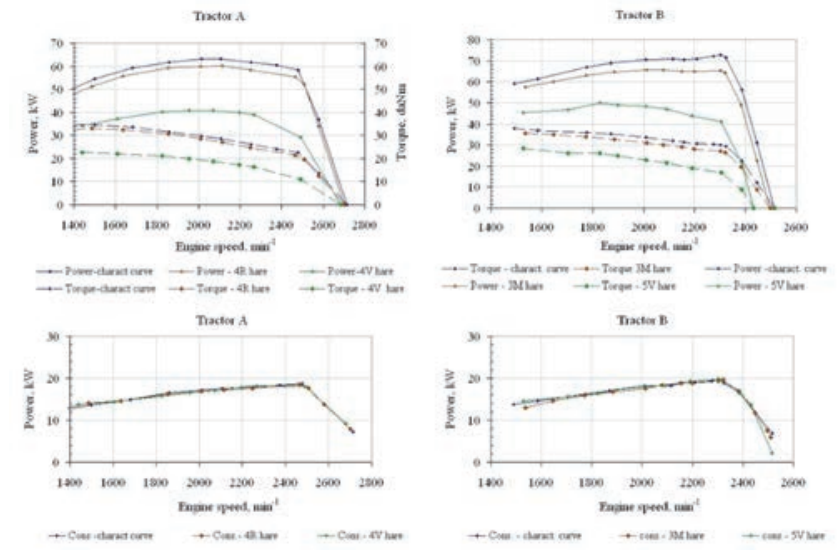

Figure 4. Engine characteristic curves under maximum fuel supply conditions. Each diagram shows the curves referred to only-engine working conditions and to the clutching of two different gears.

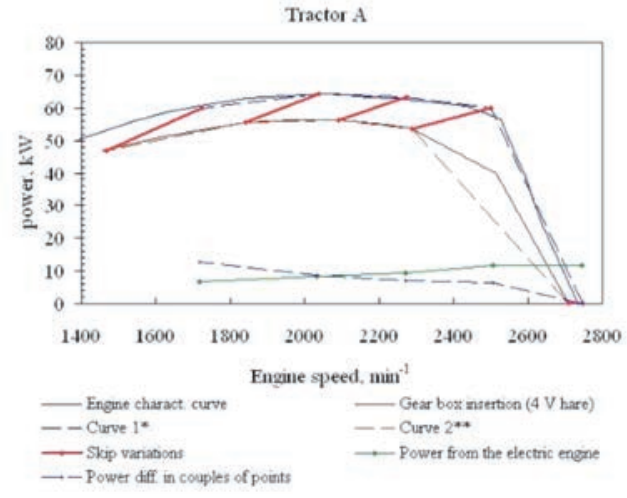

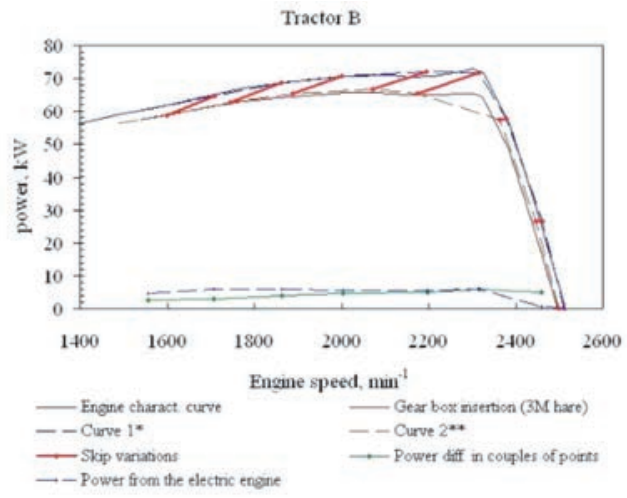

Figure 5. Tests with the electric motor. 
quence, the engine-brake system looks for a new point of balance, skipping from a curve of couple (and power) to another, with an engine speed change, at the same time, with reference to the starting value.

In the engine-brake system, such an additional resistant load (and the relative power), needed for operating any service at a certain engine speed, can be measured by means of the system based on the electric motor (2.1) used as an active system for restoring the operating conditions prior to the insertion of the gear, without disconnecting it. By applying the procedure described in 3.1.2.2, it was possible to make direct measurements of the torque applied by the electric motor and of its rotation speed, allowing to calculate the power required by the transmission, for the gear box ratio adopted. The test started from the characteristic curves at maximum fuel introduction, according to the OECD Code n. 2 . The results of these tests are reported in the diagrams of Figure 5 referred to the two tested tractors.

Each diagram shows two characteristic curves described by continuous lines: the blue line is the characteristic of the sole engine; the dark red line is the curve obtained after the insertion of a gear box ratio. Moreover, several couples of points are visible, each couple joined by a red straight line segment. The segments describe the variation of the engine working conditions (speed and power) as a consequence of the insertion of a gear box ratio (the above mentioned skipping from a curve to another). As expected, for each couple of points, one point lays on a curve (blue dashed line) overlapping the characteristic curve without gear box insertion (continuous blue line), as the other point lays on a lower curve (dark red dashed line) that coincides with the characteristic curve obtained with gear box insertion (continuous blue line).

For each couple of points, the electric motor was used to restore the initial engine speed, torque and power conditions (upper curve, as detected by the brake measuring system), The torque required by the operation was measured and multiplied by the rotation speed, directly provided the power absorbed by the gear box. Its behaviour is described by the bottom green continuous line that connects the detected points and decreases for engine speed decreases.

Finally, the bottom blue dashed line shows the behaviour of the power differences calculated in each couple of points. In describes what occurs when a gear box ratio is inserted and allows to assess the power actually available for the work. In this case it increases at engine speed decreasing.

The diagrams of Figure 6 show the results of the measurements of the gear box power requirements as a function of the peripheral velocity of tracks/wheels. For tractor A, the power increases rather constantly with the speed and a single regression curve is capable to accurately describe the behaviour. For tractor B, the behaviour I more complex because of the overlaying of the speed values of different gear ranges. For this reason, the regression curves referred to the different gear ranges are reported nearby the regression curve of all points, summarizing the average variation of power $v s$. peripheral velocity.

Further information can be achieved from the data of the power required by the transmission. Considering them as function of the engine speed at which they were observed and reporting them in the diagrams of the characteristic curves of power, provided the diagrams of Figure 7, where green coloured areas are visible, representing the power available from the engine after the insertion of the gear box ratios: of course, it decreases with engine speed, as a consequence of the greater absorption due to higher velocities. For each value of the engine speed into the interval of the green area, the available power can be calculated as the difference between the regression functions reported in the diagrams with reference to the section of the curves interested.

Finally, the Figure 8 shows the comparison between the characteristic curves of power and torque drawn, for the tractor B, with and without operating the air conditioning system in the cab. A difference of about $2 \mathrm{~kW}$ is clearly visible along the whole engine working range.

\section{Tests under operative conditions}

At present time, the stage of development of the mobile test bench includes the realization of the active system for the control of the p.t.o. power requirements, shown in Figure 9 and provisionally installed on a trailer. It is complete with sensors, data acquisition system and feedback control system.

First tests were made using the data series recorded during the work
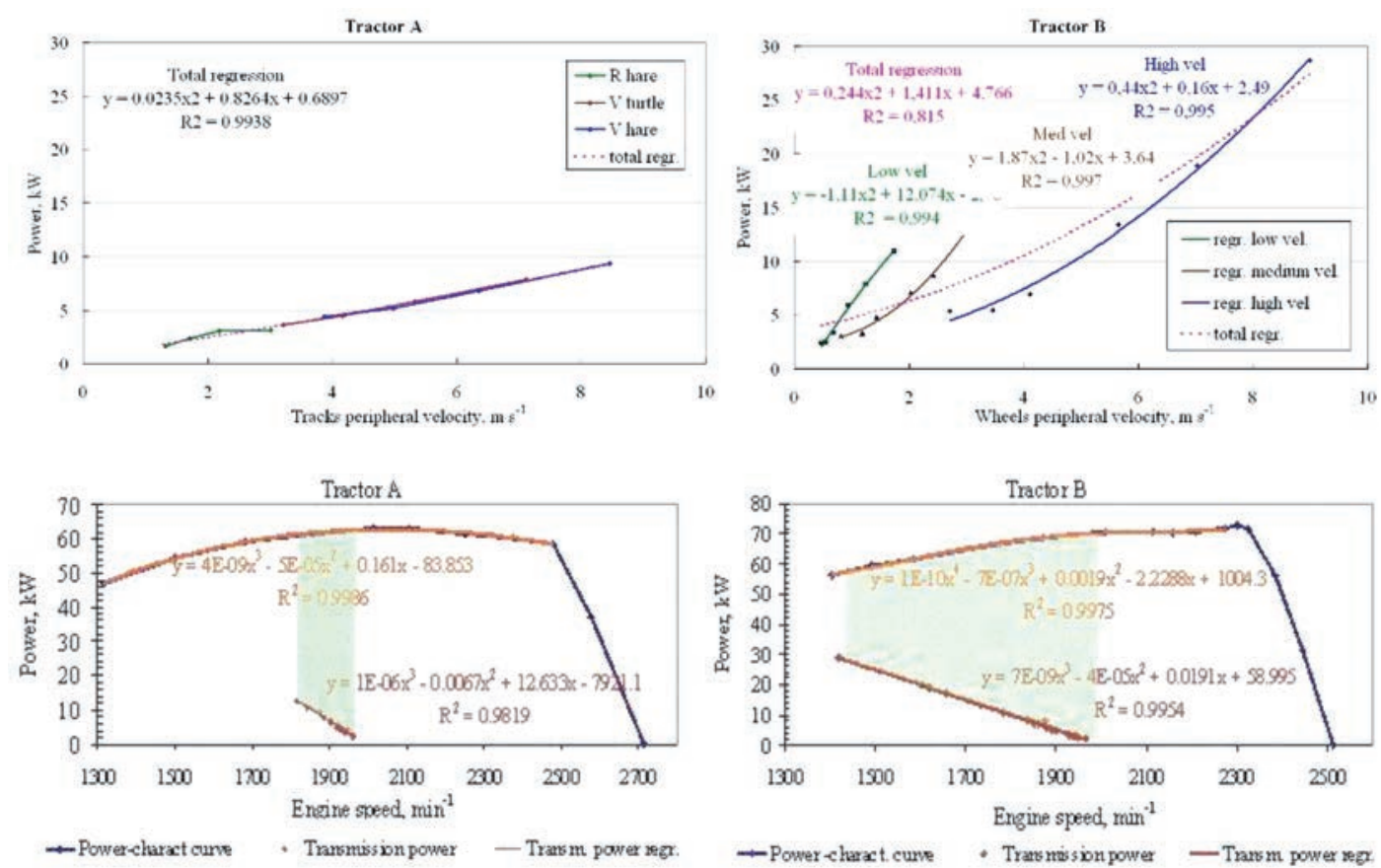

Figure 6. Power absorbed by the transmission as a

Figure 7. Power absorbed by the transmission and characteristic curves of power. The coloured areas represent the power availability cleared of the transmission requirements. 
executed by a medium dimension rotary harrow. The mobile test bench was coupled to the power take off of a $59 \mathrm{~kW}$ tractor and its control system appeared capable of correctly adjusting the values of torque, following the behaviour and the variation recorded in the field test. The development activity is going on and, at the moment, concerns the control system of the force of traction. At the same time the study is proceeding aimed at defining work cycles representative of the operational reality.

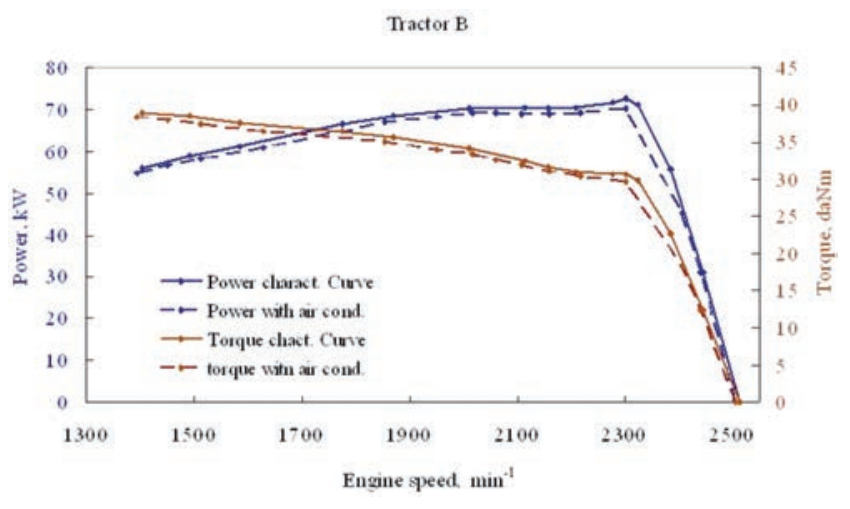

Figure 8. Power absorbed by the air conditioning system in the cab of the tractor B.
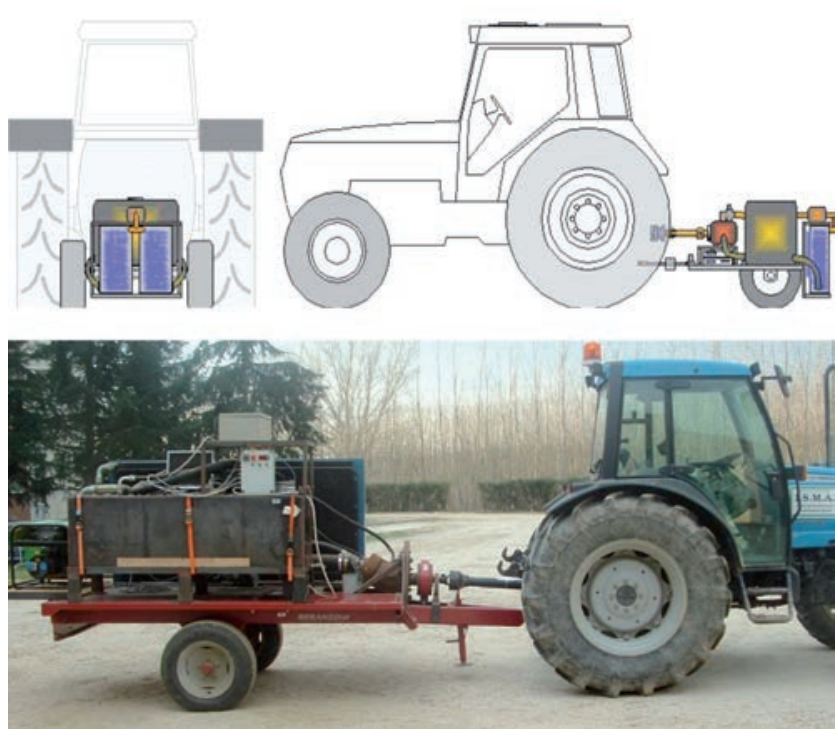

Figure 9. Mobile test bench for testing tractor power take off performances in field. It is the first step in the realization of the equipment subject of the p.t.o. project. It consists of a hydraulic dynamometric brake in which a throttle valve is electronically controlled (in feedback) with the purpose of applying the desired condition of torque (and power) measured by means of a torque meter.

\section{Conclusions}

The capability to ascertain the actual performances of a farm tractor can be increased by deepening the analysis of the functions the tractor is required to provide. Such analyses need the development of suitable methods and of the equipments for their application.

The integration between the new information and the more established methods, such as those indicated by the OECD codes, can provide a comprehensive picture of the characteristics of the tested machines, creating an instrument for guidance in the choice of operators.

The proposed insights concern both tractor tests at a fixed point and under operative condition aimed at investigating the power required by the different services such as transmission, hydraulic system, air conditioning system.

The described equipment for static tests based on the integration of a dynamometric brake and an electric motor has proven to be capable to quickly provide detailed information on the power required by mechanic transmission, as a function of the travel speed, allowing to assess the actual power available for further operations different from the displacement, depending on the initial conditions of engine operation. Further studies will determine whether the proposed system can be used with transmissions of more recent introduction (eg, those with continuous variable speed) and to define a methodology that codifies the procedures and test.

As to the tractor tests under operative conditions, the proposed test bench, still under development, will represent an additional tool capable of providing new elements for the evaluation of tractors, completing the picture resulting from the tests required by the OECD code.

\section{References}

Al-Suhaibani S.A., Al-Janobi A. A., Al-Majhadi Y. N. 2010. Development and evaluation of tractors and tillage implements instrumentation system. Am. J. of Eng. and Appl. Sci. 3 (2): 363-371.

Bodria L., Pellizzi G., Piccarolo P. 2006. Meccanica agraria Volume I - Il trattore e le macchine operatrici. Edagricole, Bologna, Italia, pp 3256 .

Casini Ropa G. 1975. A testing vehicle for checking the performance of the tractor drawbar. J. Agr. Eng. 2: 87-96.

0.E.C.D., 2012. OECD standard code for the official testing of agricultural and forestry tractor performance, Code 2, Paris Cedex, France.

Fanigliulo R., Pochi D., Volpi C., Santoro G. 2004. A mobile system to evaluate the performances of agricultural machinery under field conditions. J. Agr. Eng. 4: 89-95.

Gasparetto E., Trolli C., Viola L. 1985. Sono utili per le trattrici agricole le prove di trazione su pista?. L'Informatore Agrario 2: 43-49.

Marsili A., Servadio P. 2001. Prova in campo - Fendt 716 Vario. Macchine e Motori Agricoli 3: 34-37.

Pochi D., Ragni L., Santoro G. 1996. A mobile laboratory for the analysis of the tractor-implement-soil interactions. Third part: comparison between methodologies to evaluate the power adsorbed by implements. J. Agr. Eng. 27 (4): 193-197. 